\title{
Prediction Model for Liner Wear Considering the Motion Characteristics of Material
}

\author{
Ruiyue Liu, Boqiang Shi $(\mathbb{D}$, Yanhua Shen $\mathbb{D}$, and Guoguang Li \\ School of Mechanical Engineering, University of Science and Technology Beijing, Beijing 100083, China \\ Correspondence should be addressed to Boqiang Shi; shiboqiang@ustb.edu.cn
}

Received 4 May 2018; Accepted 16 October 2018; Published 5 November 2018

Academic Editor: Libor Pekař

Copyright (C) 2018 Ruiyue Liu et al. This is an open access article distributed under the Creative Commons Attribution License, which permits unrestricted use, distribution, and reproduction in any medium, provided the original work is properly cited.

\begin{abstract}
A generic model to explore the relationship between the parameters of cone crusher and liner wear is provided in this paper. Relative slide and squeezing between material and liner are considered based on the operating conditions, structure parameters, and material properties. The sliding distance of the material under different conditions is discussed. It is detailed how operating parameters and structural parameters influence the pressure on the liner surface. Considering that the process of liner wear evolves over time, the updating method of the geometry of crushing chamber is adopted. The wear model is derived based on Archard theory and is calibrated with the measured wear profiles of the liner from a PYGB1821 cone crusher. Experiments show that the predicted wear amount is consistent with the measured results. The wear model can be used to predict the wear state of liner and quantify the influence of operating parameters and structural parameters on the liner wear.
\end{abstract}

\section{Introduction}

Cone crushers are important comminution devices in mineral processing and cement production. While the cone crusher is working, the head assembly exerts nutation and rotation motions. The compound movement of the head makes the rock material squeezed and crushed. The liner is impacted by rock material at the moment of squeezing. At the same time, the rock material may slide along the liner surface. The impact and relative sliding lead to the wear of the liner. The liner wear directly affects the cone crusher performance and product quality, namely, different wear processes will lead to various operating performance [1-3]. Moreover, the main failure mode of the liner is wear and tear [4]. The maintenance costs caused by changing the wear parts are high [5], and the total estimated economic losses which are caused by friction and wear in mineral mining are 210,000 million Euros yearly [6]. Therefore, it is of great significance to analyze the wear of the liner and improve the performance of the crusher.

Ala-kleme [7] investigated the liner wear by the cone crusher experiment. A few siding scars were observed on the upper part of the mantle and the major wear mechanism is abrasive wear. A similar study was conducted by Clarke [8]. However, it is difficult to obtain the liner wear during operation. Thus a mathematical model of liner wear is necessary to predict the state of liner. Lindqvist [9] developed a wear model which considered the effect of normal pressure and shear forces. The pressure is related to structural parameters of the crushing chamber such as closed side setting (CSS) and eccentric angle. Asbjörnsson [10] established a wear function related to dynamic CSS. CSS is a key parameter that affects production. Ma [11, 12] showed a liner wear model, which considered the production of cone crusher. Apart from the method of mathematical modeling, Discrete Element Method (DEM) can also be used to simulate the wear process of liner. Cleary $[3,13]$ analyzed the wear process of the liner by DEM simulation and found that the liner life cycle was affected by the wear and the material flow form. Material flow form is subjected to operating conditions. Franke [14] explored the liner wear which is caused by different operating conditions. It was found that liner wear is sensitive to the speed. Moreover, Li [15] constructed the mantle and rock materials by DEM. The effect of different sliding distance and load on the liner wear was studied. Boemer [16] predicted the liner wear by DEM simulation, 


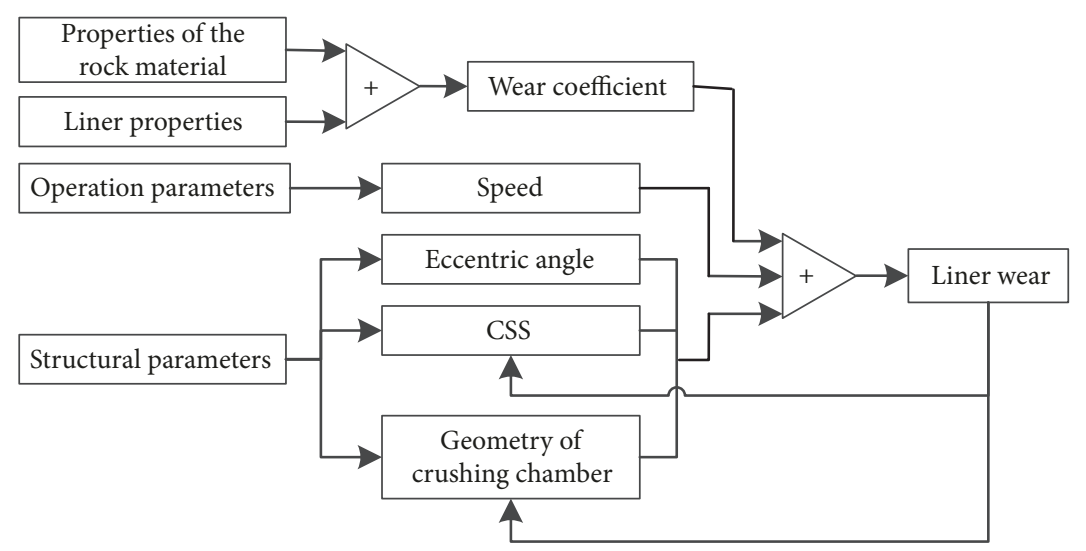

FIGURE 1: Influence factors of liner wear.

combined with wear model and replacing strategy of the geometry.

Liner wear under different CSS and production could be predicted based on the previous research. However, speed and eccentric angle are also important factors that influence the liner wear. Therefore, a mathematical model to study the influence of parameters of cone crusher on the liner wear was introduced. The model makes it possible to quantify the influence of parameters of cone crusher on the liner wear and could also be used to provide reference for further study on how to match and optimize operating parameters and structural parameters.

\section{Liner Wear Analysis}

The wear of liner surface is mainly related to load, sliding distance, the wear resistance of the liner, and the properties of the rock material $[7,17]$. Considering that the process of liner wear evolves over time [18], time should also be one of the factors considered by the wear model. Therefore, a characteristic equation of wear model can be expressed as

$$
\omega=f(p, l, W, t)
$$

where $p$ is the pressure. $l$ is sliding distance. $t$ is time of wear. Wear resistance coefficient $W$ is expressed in $\mathrm{kN} / \mathrm{mm}^{2}$ when the rock material slides along the liner surface and is expressed in $\mathrm{kN} / \mathrm{mm}^{3}$ when the rock material is squeezed by the liner.

$p$ is mainly dependent on feed size distribution and compression ratio for a given material [10, 17]. Feed size distribution is affected by material properties. Compression ratio depends on operating parameters and structural parameters of the cone crusher. As illustrated in Figure 1, material properties, liner properties, operating parameters, and structural parameters are variables which affect sliding distance [19-21]. $W$ is decided by material properties and liner properties.

\section{Prediction Model of Liner Wear}

3.1. Wear of Open Side Setting. The mantle moves cyclically from open side setting (OSS) to CSS and then backwards.
Thus the wear process of mantle can be divided into two parts according to the direction of nutation. When the mantle rotates from CSS to OSS, rock material may slide along the mantle surface. Then the liner wear may occur in the sliding zone, and the wear rate is proportional to the pressure and the sliding distance according to the Archard model [22]:

$$
\omega_{\text {open }}=\frac{P_{\text {open }} l_{\text {open }}}{W_{1}}
$$

where $W_{1}$ is wear resistance coefficient and is expressed in $\mathrm{kN} / \mathrm{mm}^{2}$. $P_{\text {open }}$ is the normal pressure of liner surface. Whether the material will slide or not is related to the base angle $\alpha_{1}$ of the mantle and friction coefficient $\mu$. If $\tan \alpha_{1}<\mu$, there is no obvious relative slide between the rock material and mantle at the CSS. Conversely, if $\tan \alpha_{1}>\mu$, sliding distance $l_{\text {open }}$ may be more than zero.

In order to obtain the sliding distance of the material along the mantle surface, the relative velocity $\boldsymbol{v}_{\mathrm{r}}$ or relative acceleration $\boldsymbol{a}_{\mathrm{r}}$ of material relative to the mantle is necessary. And they can be calculated based on the theorem of composite motion of a point. As the mantle surface is in rotation, the absolute acceleration $\boldsymbol{a}_{\mathrm{a}}$ of material is the vector sum of the transport acceleration $\boldsymbol{a}_{\mathrm{e}}$, the relative acceleration and the Coriolis acceleration $\boldsymbol{a}_{\mathrm{c}}$. Thus, the absolute acceleration of rock material can be presented as

$$
\begin{aligned}
\boldsymbol{a}_{\mathrm{a}} & =\boldsymbol{a}_{\mathrm{e}}+\boldsymbol{a}_{\mathrm{r}}+\boldsymbol{a}_{\mathrm{c}} \\
& =\boldsymbol{\alpha} \times \mathbf{r}+\boldsymbol{\omega} \times(\boldsymbol{\omega} \times \mathbf{r})+\boldsymbol{a}_{\mathrm{r}}+2\left(\boldsymbol{\omega} \times \boldsymbol{v}_{\mathrm{r}}\right)
\end{aligned}
$$

where $\boldsymbol{\alpha}$ is the angular acceleration of mantle. $\boldsymbol{r}$ is the radius of moving point $A$, as can be seen from Figure 2. $\omega$ is angular velocity of mantle (the appendix).

Then projecting $\boldsymbol{a}_{\mathrm{e}}, \boldsymbol{a}_{\mathrm{r}}$, and $\boldsymbol{a}_{\mathrm{c}}$ to axis $\xi$ and $\eta$ yields

$$
\begin{aligned}
& a_{\xi}=2 \omega v_{\mathrm{r}}+\alpha r \cos \psi-\omega^{2} r \sin \psi \\
& a_{\eta}=a_{\mathrm{r}}^{t}+\alpha r \sin \psi-\omega^{2} r \cos \psi
\end{aligned}
$$

where $\psi$ is the angle between axis $\xi$ and tangential acceleration. $a_{\xi}$ and $a_{\eta}$ are acceleration along axis $\xi$ and $\eta$, respectively. 


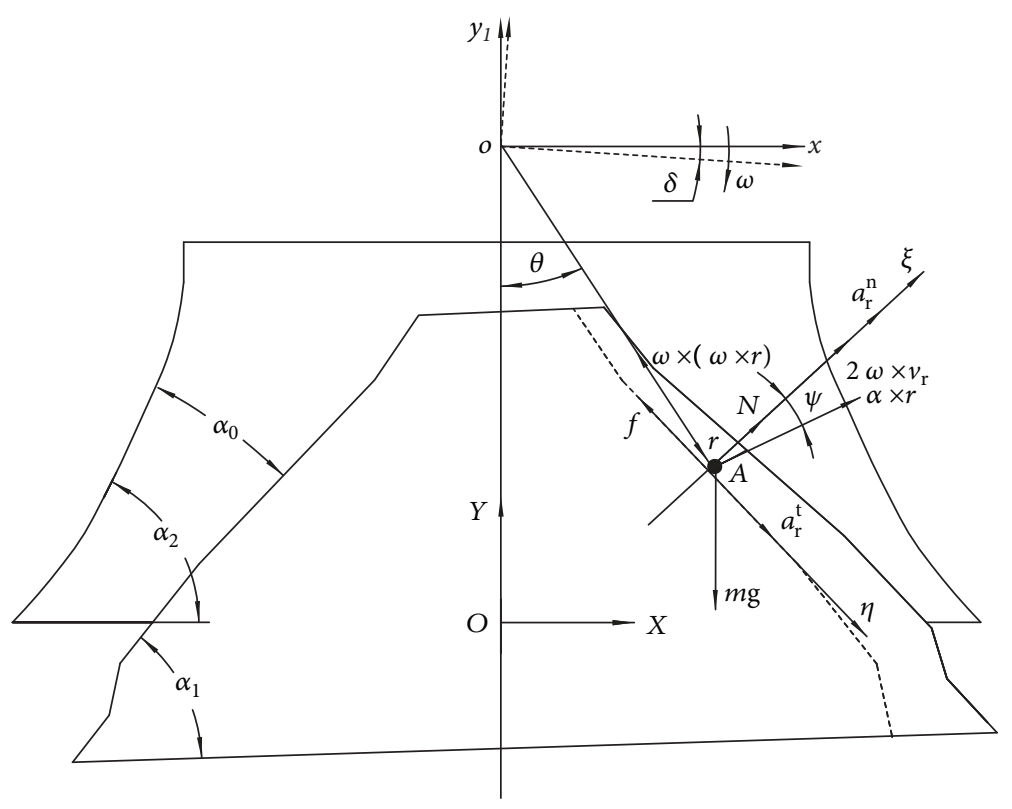

FIgURE 2: Motion of material relative to a moving coordinate.

However, $\boldsymbol{v}_{\mathrm{r}}$ and $\boldsymbol{a}_{\mathrm{r}}$ cannot be calculated only based on (4). Therefore, it is necessary to analyze the force of material. According to Newton's second law, equations of motion of rock material can be written as

$$
\begin{array}{r}
m g \cos \left(\alpha_{1}+\delta\right)-N=m a_{\xi} \\
\mu N-m g \sin \left(\alpha_{1}+\delta\right)=m a_{\eta}
\end{array}
$$

where $\delta$ is the angle between fixed axis and moving axis. $g$ is gravitational acceleration. $m$ is the mass of rock material.

Next, a first order differential equation with a variable $v_{\mathrm{r}}$ can be obtained by combining (4) and (5).

$$
\begin{aligned}
\dot{v}_{\mathrm{r}}+ & 2 \mu \omega v_{\mathrm{r}}+\alpha r(\mu \cos \psi+\sin \psi) \\
& -\omega^{2} r(\mu \sin \psi+\cos \psi) \\
& -g\left[\mu \cos \left(\alpha_{1}+\delta\right)-\sin \left(\alpha_{1}+\delta\right)\right]=0
\end{aligned}
$$

When the parameters of cone crusher are given, relative velocity and relative acceleration can be solved according to (6). Finally, liner wear of OSS can be written as

$$
\begin{aligned}
& \omega_{\text {open }} \\
& =\frac{1000 M\left[g \cos \left(\alpha_{1}+\delta\right)-2 \omega v_{\mathrm{r}}-\alpha r \cos \psi+\omega^{2} r \sin \psi\right] \int_{0}^{t_{\mathrm{s}}} v_{\mathrm{r}} d t}{W_{1}}
\end{aligned}
$$

where $t_{\mathrm{s}}$ is sliding time. $M$ is the mass of rock material per square millimeter and is expressed in $\mathrm{kg} / \mathrm{mm}^{2}$.

3.2. Wear of Closed Side Setting. The other part of wear is mainly caused by the compressive pressure when the mantle rotates from OSS to CSS. The mantle surface will be worn during the crushing process whether there is relative slide or not. In fact, there is no obvious relative slide between the rock material and mantle at the CSS [9]. Thus, the wear amount of mantle can be presented as

$$
\omega_{\text {closed }}=\frac{\left[\left(P_{\mathrm{n}}+P_{\mathrm{N}}\right)+K\left(P_{\mathrm{t}}+\mu P_{\mathrm{N}}\right)\right]}{W_{2}}
$$

where $W_{2}$ is wear resistance coefficient and is expressed in $\mathrm{kN} / \mathrm{mm}^{3} . K$ is shear force coefficient. $P_{\mathrm{N}}$ is the pressure caused by the gravity of rock material. $P_{\mathrm{n}}$ and $P_{\mathrm{t}}$ are normal pressure and shear stress, respectively; they are related to compression ratio $i$, feed size distribution coefficient $\sigma$, and nip angle $\alpha_{0}$.

$$
\begin{aligned}
& P_{\mathrm{n}}=p(i, \sigma) \\
& P_{\mathrm{t}}=P_{\mathrm{n}} \tan \frac{\alpha_{0}}{2}
\end{aligned}
$$

$i$ is the ratio of compression amount to the height before compression. In the cone crusher, compression amount is stroke $s$. As can be seen from Figure 3, the height $b$ before compression is the distance between mantle and bowl liner. Thus

$$
i=\frac{s}{b}
$$

where

$$
\begin{aligned}
s & =2 \gamma_{0} \sqrt{R_{1}^{2}+y^{2}} \\
b & =c s s+s \\
c s s & =R_{2}-R_{1}-\gamma_{0} \sqrt{R_{1}^{2}+y^{2}}
\end{aligned}
$$



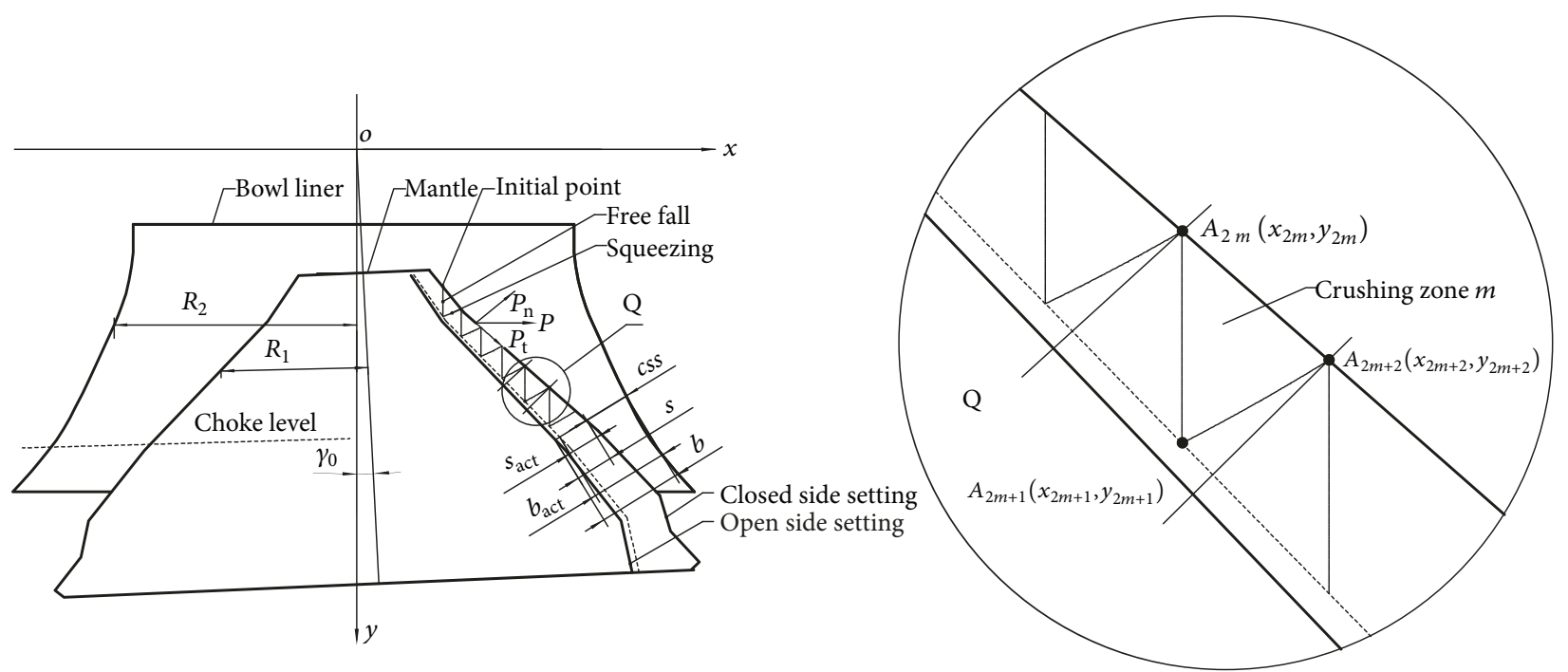

Figure 3: Sectional drawing of the liner.

where $\gamma_{0}$ is the eccentric angle. $R_{1}$ and $R_{2}$ are the radius of mantle and bowl liner, respectively. css is the distance between bowl liner and the mantle at the CSS.

Then compression ratio can be calculated according to (11)-(14). However, the compression ratio may not be equal to the actual compression ratio when the crusher operates in different conditions. As is shown in Figure 3, the compression ratio $i$ is more than the actual compression ratio $i_{\text {act }}$ when the material passes through the crushing chamber by free fall [23]. Taking crushing zone $m$ as an example, material is in free fall from $A_{2 m}$ to $A_{2 m+1}$. Then it is squeezed to point $A_{2 m+2}$. Their coordinates are as follows: $\left(x_{2 m}, y_{2 m}\right),\left(x_{2 m+1}, y_{2 m+1}\right)$, and $\left(x_{2 m+2}, y_{2 m+2}\right)$. Squeezing time is $t_{2 m}$. $k$ is the actual stroke coefficient. When the initial coordinates are given, $i_{\text {act }}$ can be calculated according to Figure 4.
The other influence factor of crushing pressure is size distribution coefficient $\sigma$. It represents the dispersion of particle size:

$$
\sigma=\frac{1}{\bar{d}} \sqrt{\sum_{u=1}^{q} \lambda_{u}\left(d_{u}-\bar{d}\right)^{2}}
$$

where $\lambda_{u}$ is the yield of particle size $m . q$ is the number of particle sizes. $d_{u}$ is determined by the mean size of particle $u$. $\bar{d}$ is the average size of all particles.

Next, $i_{\text {act }}$ and $\sigma$ can be used to readily estimate the crushing pressure according to (9). Finally, the wear of CSS can be written as follows.

$$
\omega_{\text {closed }}=\frac{\left(1+K \tan \left(\alpha_{0} / 2\right)\right) p\left(i_{\text {act }}, \sigma\right)}{W_{2}}+\frac{1000 M(1+K \mu)\left[g \cos \left(\alpha_{1}+\delta\right)-2 \omega v_{\mathrm{r}}-\alpha r \cos \psi+\omega^{2} r \sin \psi\right]}{W_{2}}
$$

3.3. Wear Model of Liner. The wear of OSS and CSS can be calculated according to (2) and (8). The sum of $\Phi_{\text {open }}$ and $\omega_{\text {closed }}$ equals the liner wear $\omega$.

$$
\omega=\omega_{\text {open }}+\omega_{\text {closed }}
$$

Then according to (17), mantle wear per revolution can be obtained. However, the wear process of the liner evolves with time. The geometry of mantle varies with time. The compression ratio will decrease correspondingly according to (11). It is assumed that the wear amount of the mantle is equal to the bowl liner. Chamber geometry was updated by replacing their vertices on the basis of the wear amount per stroke. Next $i_{\text {act }}$ can be written as

$$
i_{\text {act }}(N)=\frac{2 k \gamma_{0} \sqrt{R_{1}^{2}+y^{2}}}{c s s+2 k \gamma_{0} \sqrt{R_{1}^{2}+y^{2}}+2 \omega(N-1)}
$$

$$
N \geq 1
$$

where initial wear $₫(0)$ is zero.

Finally the wear amount after $N$ strokes can be written as (19) according to Figure 5.

$$
\varpi(N)=\frac{1000 M\left[g \cos \left(\alpha_{1}+\delta\right)-2 \omega v_{\mathrm{r}}-\alpha r \cos \psi+\omega^{2} r \sin \psi\right] \int_{0}^{t_{s}} v_{r} d t}{W_{1}}
$$




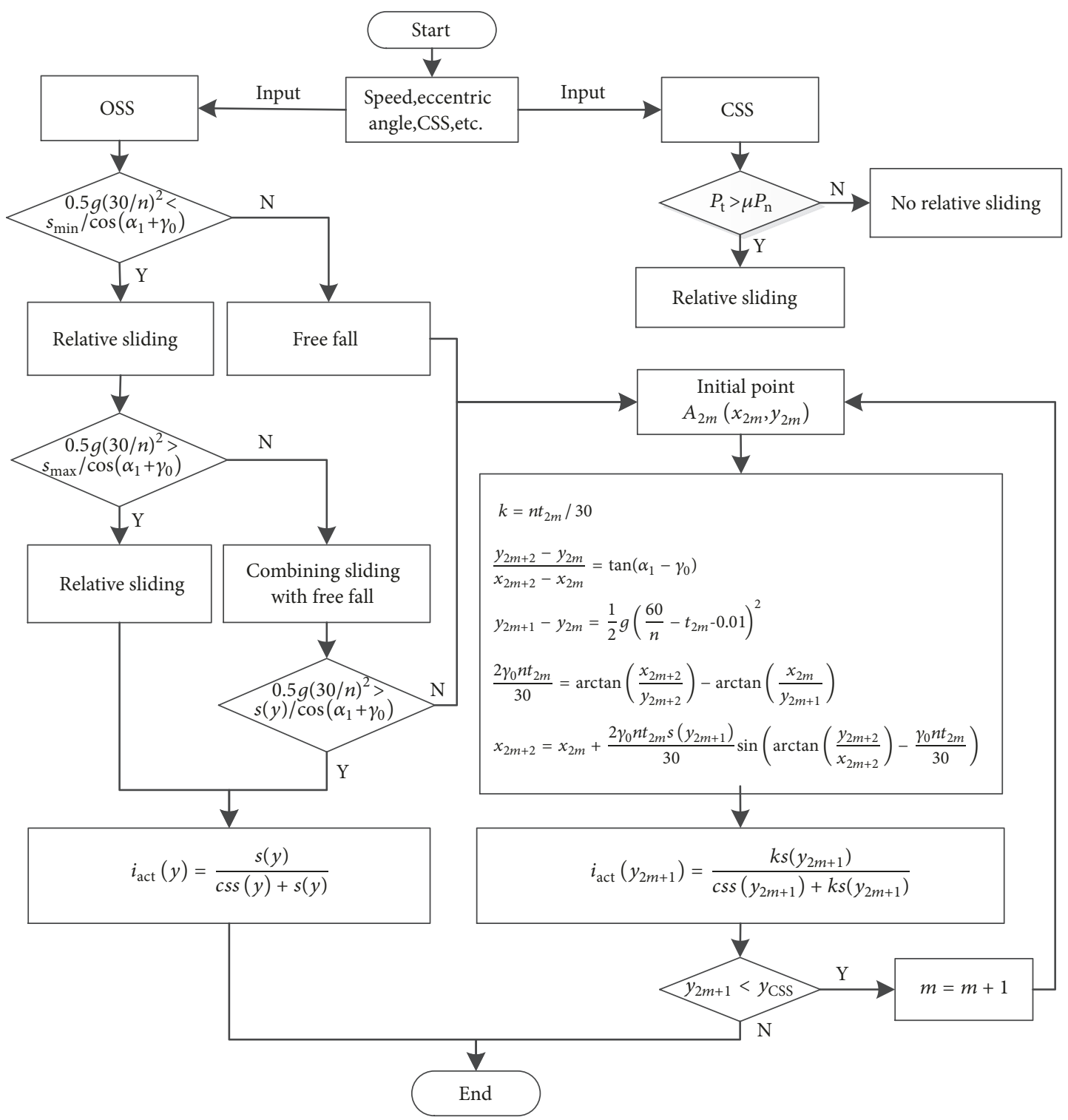

FIGURE 4: Flow chart of actual compression ratio.

$$
\begin{aligned}
& +\frac{1000 M(1+K \mu)\left[g \cos \left(\alpha_{1}+\delta\right)-2 \omega v_{\mathrm{r}}-\alpha r \cos \psi+\omega^{2} r \sin \psi\right]}{W_{2}} \\
& +\frac{\left(1+K \tan \left(\alpha_{0} / 2\right)\right) p\left(2 k \gamma_{0} \sqrt{R_{1}^{2}+y^{2}} /\left(c s s+2 k \gamma_{0} \sqrt{R_{1}^{2}+y^{2}}+2 \omega(N-1)\right), \sigma\right)}{W_{2}}+\omega(N-1)
\end{aligned}
$$

\section{Example}

4.1. Experiment. In order to study the liner wear of cone crusher, a series of experiments were conducted on a PYGB1821 crusher at Anshan Iron and Steel Group Mining Co., Ltd. A laser profiler device for measuring the worn geometry of liner was used. The technique used in the present study, to measure the wear of liner, was similar to the technique used by Rosario [24]. The measurement of liner wear was conducted after $120 \mathrm{~h}$ of operation. Wear amount of the liner was measured on a 20 by 8 grid with $25 \mathrm{~mm}$ spacing on each liner. The average wear amount on each level in the downward direction can be computed. The bowl is moved upward every two hours in order to maintain the CSS. Parameters of cone crusher and feed size distribution were as shown in Table 1. 


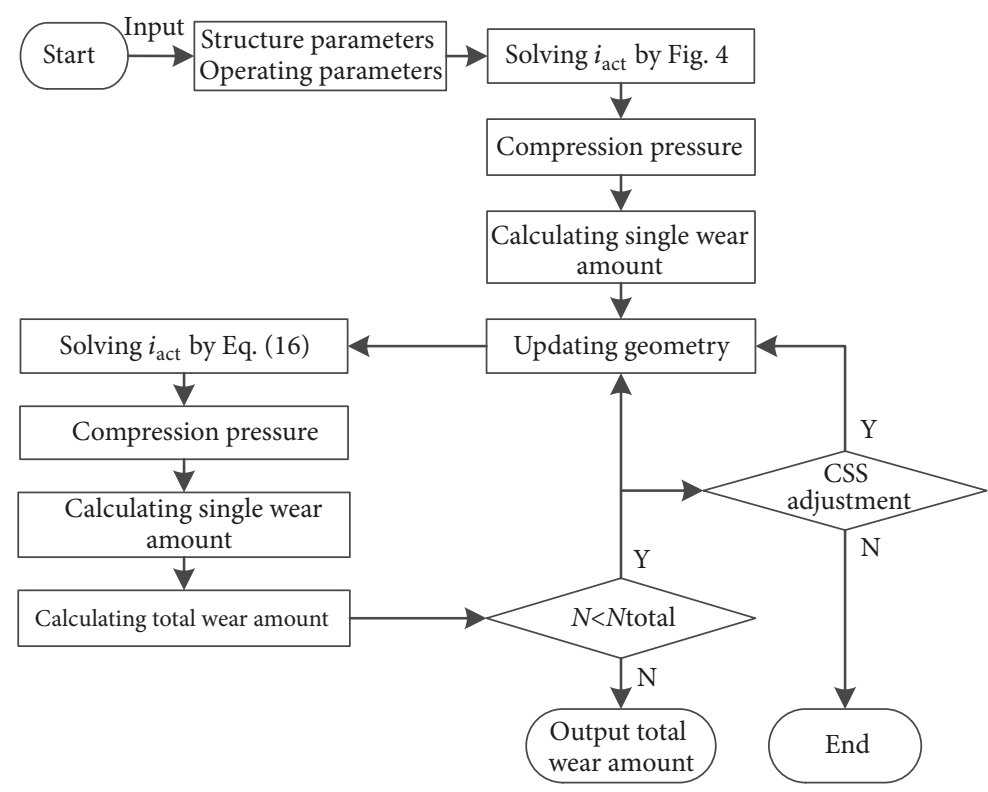

FIGURE 5: Flow chart of wear calculation.

TABLE 1: Parameters of cone crusher.

\begin{tabular}{lc}
\hline Coefficient & Value \\
\hline Abscissa of initial point $(\mathrm{mm})$ & 187.8 \\
Ordinate of initial point $(\mathrm{mm})$ & 333.3 \\
Choke level $(\mathrm{mm})$ & 727 \\
Base angle of mantle $\left(^{\circ}\right)$ & 50.5 \\
Nip angle $\left({ }^{\circ}\right)$ & 21 \\
Eccentric angle $\left(^{\circ}\right)$ & 2.5 \\
CSS $(\mathrm{mm})$ & 19 \\
Speed $(\mathrm{r} / \mathrm{min})$ & 300 \\
\hline
\end{tabular}

Table 2 shows the feed particle size distribution [23].

The friction coefficient between mantle and rock material can be obtained by tribological test and it was carried out on a wear tester (CETR UMT, USA). The friction coefficient between mantle and rock material was 0.26 . The squeezing wear resistance can be measured by compression experiment. The method resembled the one used by Lindqvist [25]. The coefficients of sliding wear resistance and squeezing wear resistance were $229 \mathrm{kN} / \mathrm{mm}^{2}$ and $279 \mathrm{kN} / \mathrm{mm}^{3}$, respectively. The value of shear wear factor $K$ was 50 [9]. Moreover, crushing pressure is also necessary to estimate the wear of mantle. The crushing pressure can be obtained by comminution tests [11]. First the rock material was compressed in a piston and die equipment to different compression ratios. Then the pressure and compression ratios, which were recorded at the tests, are used to obtain the regression equation of pressure $p$ on unit area.

$$
\begin{aligned}
p(i, \sigma)= & i^{2}\left(-263.01 \sigma^{2}+393.673 \sigma-51.603\right) \\
& +i\left(189.563 \sigma^{2}-127.947 \sigma+51.452\right)
\end{aligned}
$$

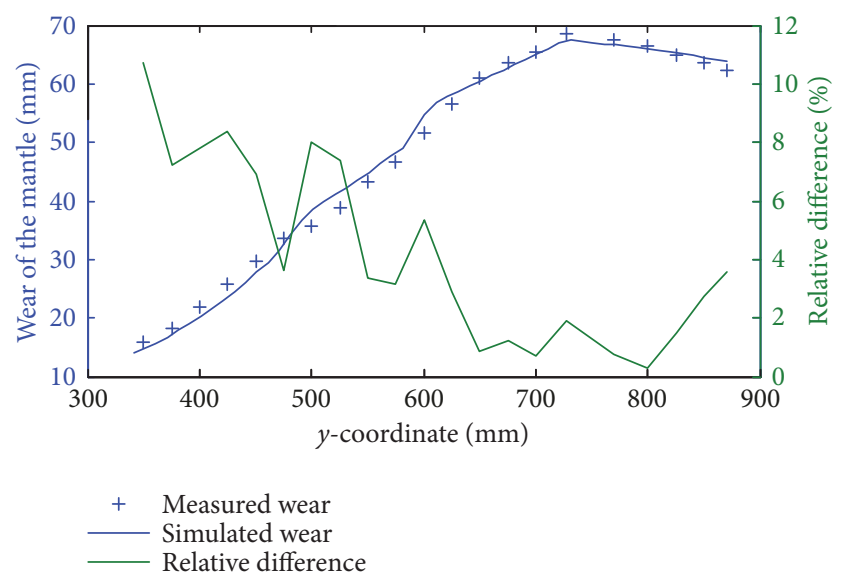

FIGURE 6: Measured and simulated value of mantle wear over $120 \mathrm{~h}$ of operation.

4.2. Model versus Measurements. The surface wear of the liner can be obtained by (18) and (19). Figure 6 shows the comparison of the simulated and measured worn profiles. The predicted results show that wear amount is low at the entrance of the crushing chamber and the sliding wear accounts for about $4.6 \%$ of the total wear, while the wear amount reaches the maximum near the choke level. The result is similar to the findings of Delaney [13]. This can be attributed to the fact that the compression ratio is relatively low at the entrance of the crushing chamber. Besides, the particle size is larger than that of choke level. The larger particles have a higher probability of containing defects, which means that the compressive pressure is small. Thus, the wear is less severe. Similar trends can also be observed in the experiments. The experimental results are in accord with the predicted results. 
TABLE 2: Feed particle size distribution.

\begin{tabular}{|c|c|c|c|}
\hline \multirow{3}{*}{ Particle size $(\mathrm{mm})$} & \multicolumn{3}{|c|}{ Feed size distribution (\%) } \\
\hline & \multicolumn{3}{|c|}{ Test number } \\
\hline & 1 & 2 & 3 \\
\hline+100 & 2.51 & 4.13 & 1.87 \\
\hline$-100 \sim+66$ & 8.69 & 13.25 & 12.05 \\
\hline$-66 \sim+42$ & 19.42 & 16.73 & 22.03 \\
\hline$-42 \sim+30$ & 19.39 & 18.34 & 17.92 \\
\hline$-30 \sim+24$ & 15.13 & 12.72 & 11.35 \\
\hline$-24 \sim+12$ & 30.31 & 32.17 & 30.77 \\
\hline$-12 \sim+7$ & 3.34 & 1.97 & 3.52 \\
\hline$-7 \sim+5$ & 0.27 & 0.13 & 0.29 \\
\hline$-5 \sim 0$ & 0.94 & 0.56 & 0.20 \\
\hline
\end{tabular}
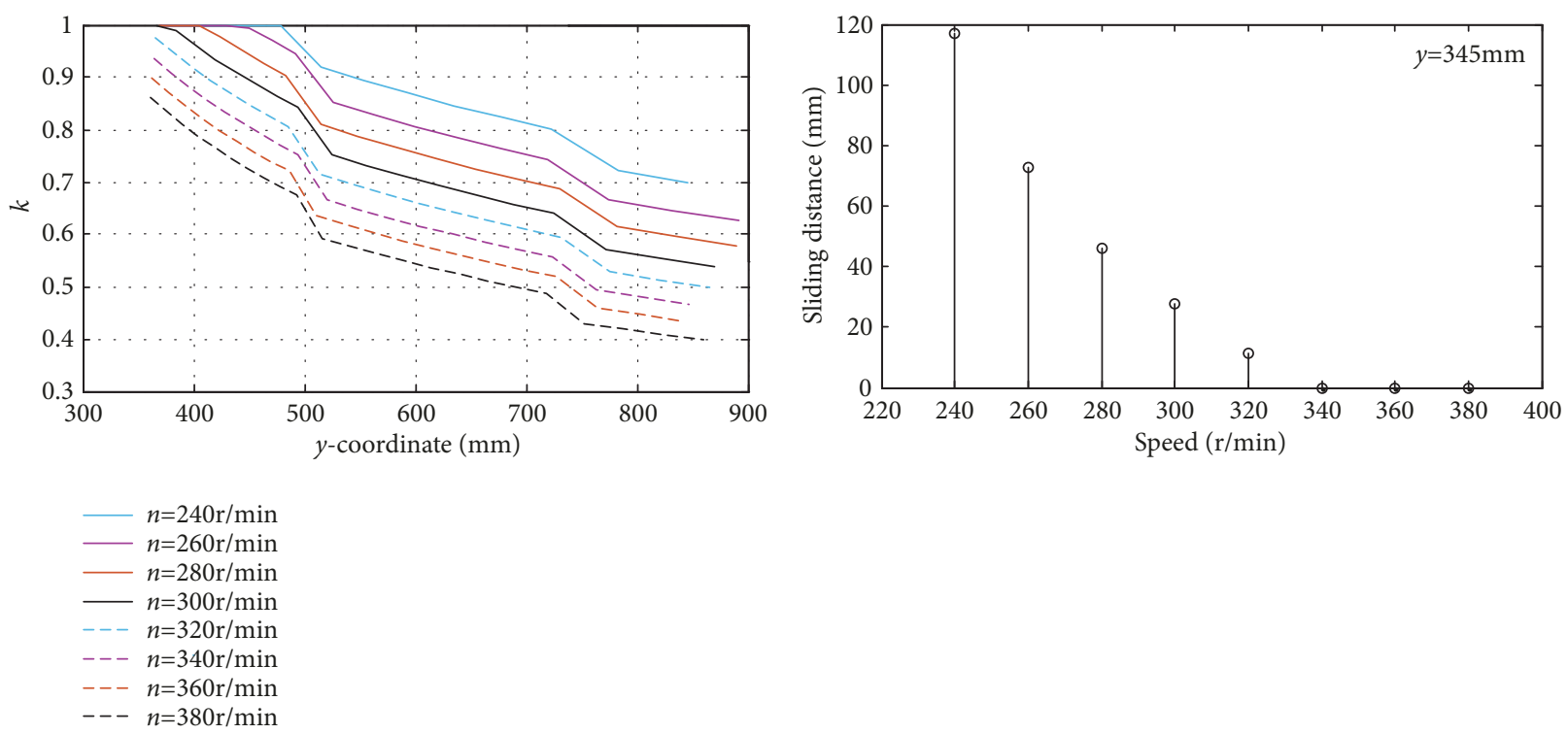

(a)

(b)

Figure 7: Actual stroke coefficient and sliding distance under different speed. (a) Actual stroke coefficient. (b) Sliding distance per stroke.

4.3. Influencing Factors of Liner Wear. Liner wear is influenced by the pressure and distance according to (7). For a given material, the pressure is primarily depends on the compression ratio, and the compression ratio is mainly related to speed, eccentric angle, and CSS. As illustrated in Figure $7(\mathrm{a})$, the actual stroke coefficient presents a downward trend with the increase of speed. Namely, the higher the speed is, the lower the compression ratio becomes. The other influence factor of liner wear, sliding distance, is shown in Figure 7(b). The sliding distance decreases sharply with an increase in speed.

Therefore the wear amount per stroke will decrease with an increase in speed, as shown in Figure 8(a). However, this does not mean that the total wear of liner presents a downward tendency with the increase of speed, as illustrated in Figure $8(\mathrm{~b})$. The liner wear not only is related to wear amount per stroke, but also has a close relationship with stroke times. Therefore, wear amount of liner may fluctuate with an increase in speed. The predicted wear amount of choke level reaches its lowest point at the speed of $349 \mathrm{rpm}$. Nevertheless, the rotation speed at the minimum wear rate may be different when the feed material or structure parameters change.

The structure parameter, eccentric angle, has a positive correlation with liner wear. The eccentric angle is proportional to $s$, and $b$ is almost invariant. Accordingly, it can be concluded that compression ratio follows with the increase of eccentric angle, as does the pressure. Therefore, liner wear increases with an increase in eccentric angle, as shown in Figure 9. The growth rate of liner wear is maximum at the speed of $240 \mathrm{rpm}$, while being minimum at the speed of $349 \mathrm{rpm}$. Moreover, the liner wear of choke level is about 1.45 times as much as that of $1.1^{\circ}$ when the eccentric angle is $2.5^{\circ}$.

Last but not least, CSS also has an important influence on liner wear and can be regulated by adjusting the height of the bowl. Then liner wear for various CSS is calculated according to (18). It is clear from Figure 10(a) that the liner wear decreases with the increase of CSS and also in a nonlinear way. This is in turn consistent 


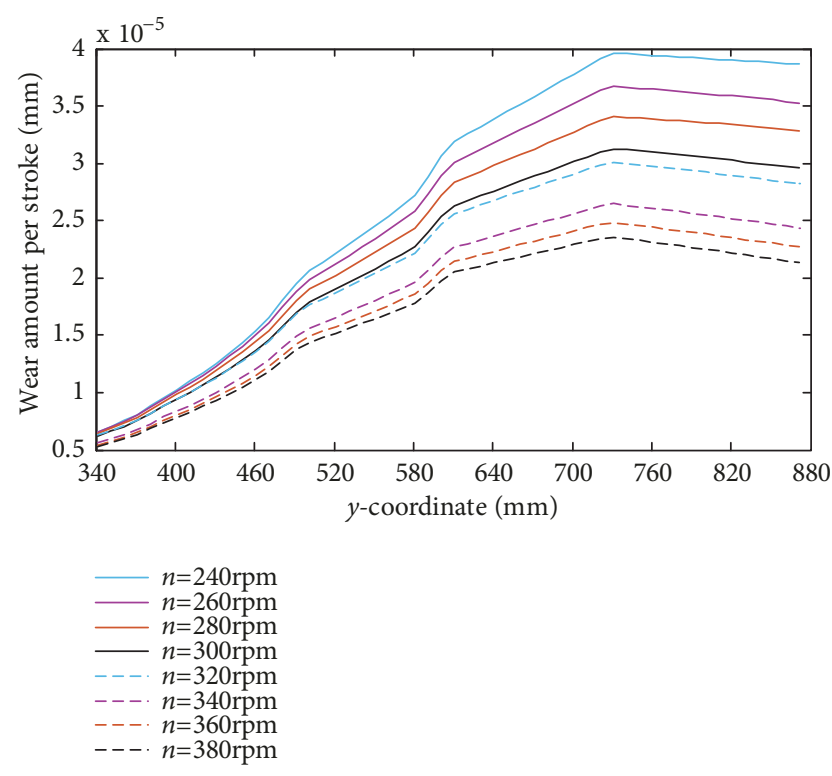

(a) $\gamma_{0}=2.5^{\circ}, \mathrm{CSS}=19 \mathrm{~mm}$

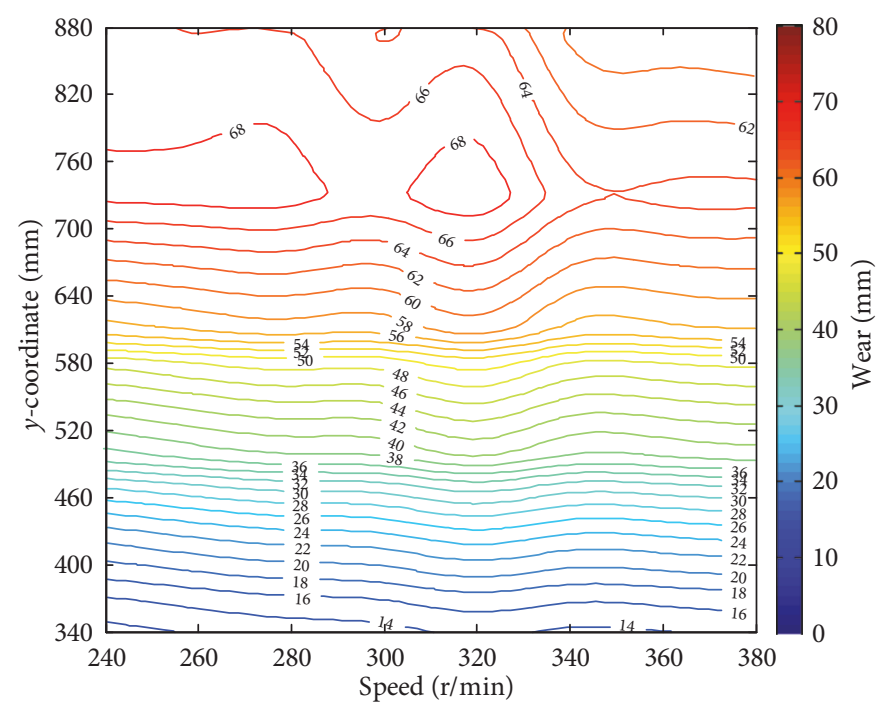

(b) $\gamma_{0}=2.5^{\circ}$, CSS $=19 \mathrm{~mm}$

FIGURE 8: Wear amount with speed ranging from $240 \mathrm{rpm}$ to $380 \mathrm{rpm}$. (a) Wear amount per stroke. (b) Mantle wear.

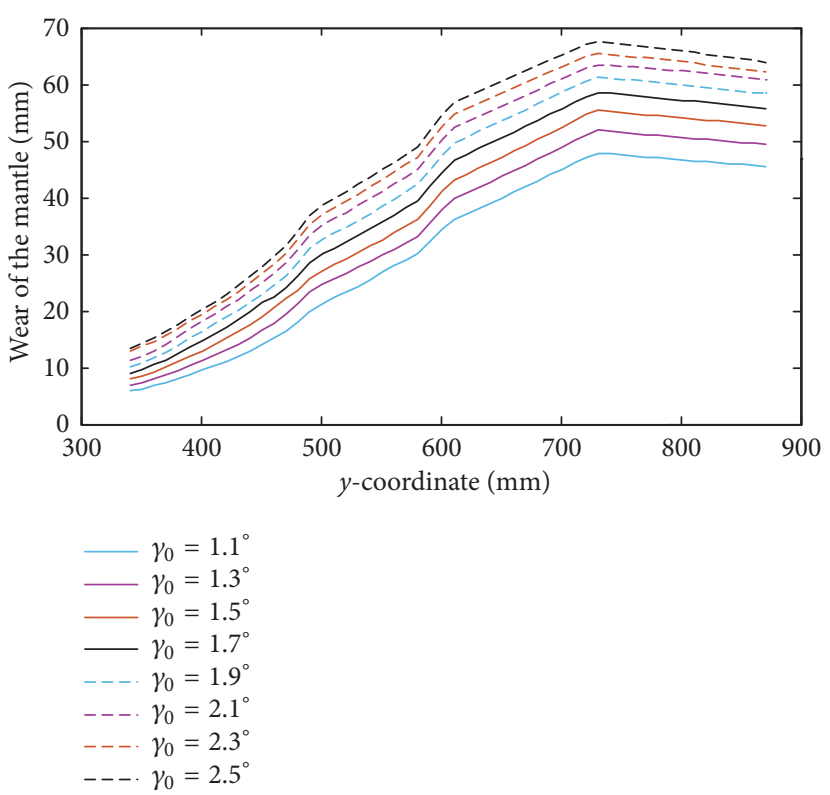

(a) $n=300 \mathrm{rpm}, \mathrm{CSS}=19 \mathrm{~mm}$

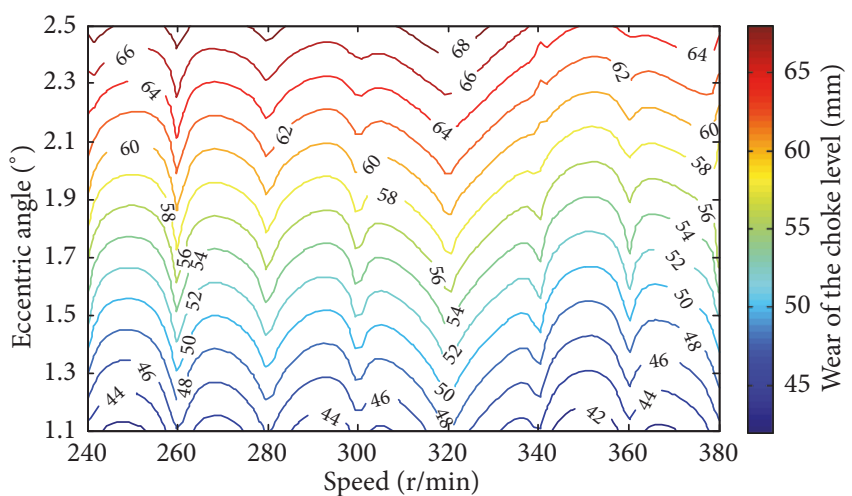

(b) $y=727 \mathrm{~mm}, \mathrm{CSS}=19 \mathrm{~mm}$

Figure 9: Wear amount with eccentric angle ranging from $1.1^{\circ}$ to $2.5^{\circ}$. (a) Mantle wear. (b) Maximum wear at different eccentric angle and speed.

with the findings of Asbjörnsson [10]. Since CSS is one of the most important factors in determining the product size. The bigger the CSS is, the bigger the average product size becomes. Then the pressure will decrease due to the increase of CSS, and so does liner wear. Nevertheless, the increase of CSS will lead to the production improvement. The production and wear amount show a reverse variation trend with an increase in CSS. Figure 10(b) indicates that the wear amount per unit weight has a negative correlation with CSS. The influence of CSS on the wear amount per unit weight is more notable at the lower end than that at the top part, which is similar to the speed. The influence of speed on the wear of choke level is shown in Figure 10(c). Within the speed range of $240 \mathrm{rpm}$ to $380 \mathrm{rpm}$, the speed of most series of wear is $318 \mathrm{rpm}$, while the minimum is $349 \mathrm{rpm}$. 


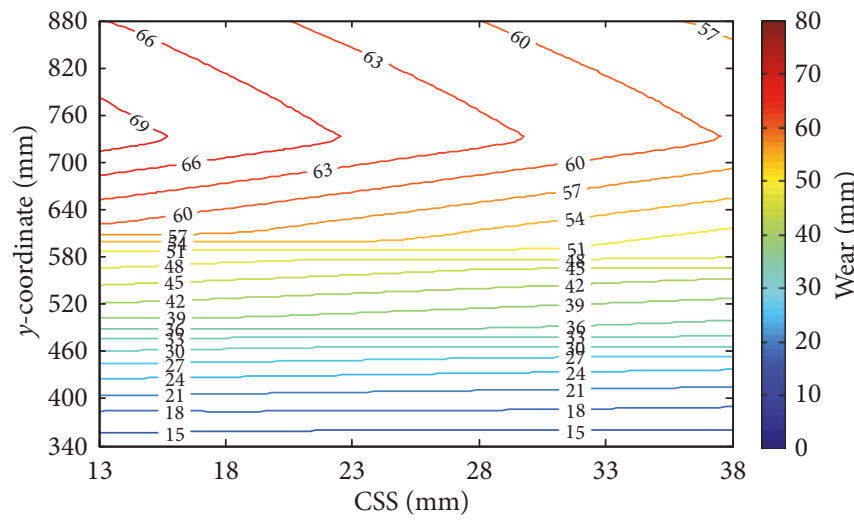

(a) $n=300 \mathrm{rpm}, \gamma_{0}=2.5^{\circ}$

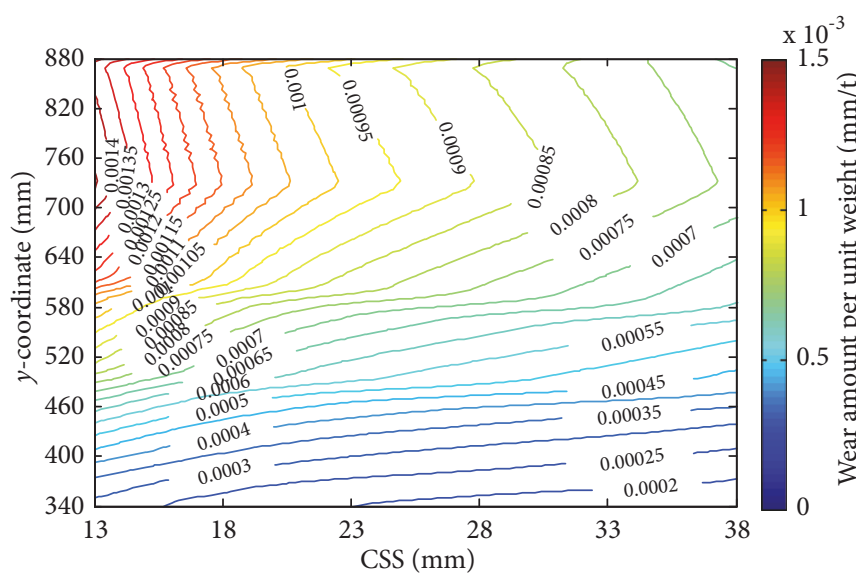

(b) $n=300 \mathrm{rpm}, \gamma_{0}=2.5^{\circ}$

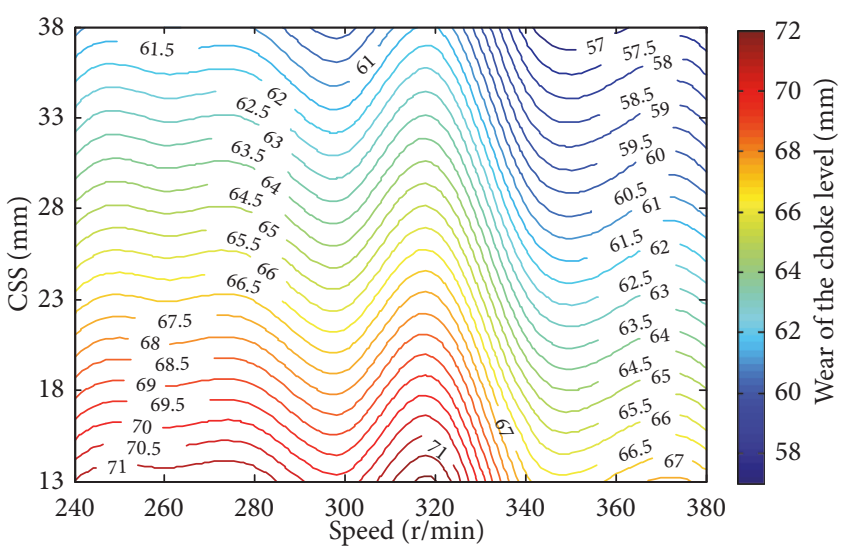

(c) $y=727 \mathrm{~mm}, \gamma_{0}=2.5^{\circ}$

FIGURE 10: Wear amount with CSS ranging from $13 \mathrm{~mm}$ to $38 \mathrm{~mm}$. (a) Mantle wear. (b) Wear amount per unit weight. (c) Maximum wear at different CSS and speed.

\section{Conclusions}

(1) A liner wear model which considered the operating conditions and structural parameters of a crushing chamber was developed based on the Archard theory and it had been calibrated and validated based on a PYGB1821 cone crusher.

(2) Speed and eccentric angle are some of those factors that decided whether there is sliding wear or not. When the speed and eccentric angle are $300 \mathrm{rpm}$ and $2.5^{\circ}$, respectively, the sliding wear at the entrance of the crushing chamber is about $4.6 \%$ of total wear.

(3) Maximum liner wear will fluctuate with the increase of speed when the speed is in the range of $200 \mathrm{rpm}$ to $400 \mathrm{rpm}$. The speed of $318 \mathrm{rpm}$ should be avoided from the point of view of wear.

(4) The liner wear follows with the increase of the eccentric angle and the growth trend gradually slows down. When the CSS is $19 \mathrm{~mm}$, the maximum liner wear at the eccentric angle of $2.5^{\circ}$ is about 1.45 times as much as that at $1.1^{\circ}$.

(5) Liner wear decreases nonlinearly with an increase in CSS. When the eccentric angle is an angle of $2.5^{\circ}$, an increase in CSS from $13 \mathrm{~mm}$ to $38 \mathrm{~mm}$ led to a decrease of about $14.8 \%$ of wear at the choke level.

(6) The model provides a means for quantifying the influence of parameters of cone crusher on the liner wear and also could be used to supply a reference for further study on how to match and optimize parameters of cone crusher.

\section{Appendix}

Angular velocity and angular acceleration of mantle:

The angular velocity $\omega$ and angular acceleration $\alpha$ of mantle can be obtained by differentiating equation according to its law of motion.

$$
\begin{aligned}
& \omega=\frac{1}{r} \frac{d s(\beta)}{d \beta} \frac{d \beta}{d t}=\frac{2 \pi n}{60 r} \frac{d s(\beta)}{d \beta} \\
& \alpha=\frac{\mathrm{d} \omega}{\mathrm{d} t}
\end{aligned}
$$

where $r$ is the distance between the mantle surface and suspension point $O_{1} . s(\beta)$ is the stroke when the mantle rotates angle $\beta$. 


$$
\begin{aligned}
r= & \sqrt{{R_{1}{ }^{2}+y^{2}}^{2}} \\
s(\beta)= & \sqrt{{R_{1}{ }^{2}-0.25 s^{2} \sin ^{2}(\beta)}^{2}-\frac{s \cos (\beta)}{2}+0.5 s} \\
& -R_{1} \\
\beta= & \frac{\pi n t}{30}
\end{aligned}
$$

Then substituting the derivative of $s(\beta)$ into (A.1) gives the following.

$$
\omega=\frac{2 \pi n}{60 r}\left(-\frac{s^{2} \sin (2 \beta)}{8 \sqrt{R_{1}^{2}-0.25 s^{2} \sin ^{2}(\beta)}}+\frac{s \sin (\beta)}{2}\right)
$$

Finally the angular acceleration of mantle is expressed as follows.

$$
\begin{aligned}
\alpha(t) & =\frac{\mathrm{d} \omega(t)}{\mathrm{d} t} \\
& =\frac{\pi^{2} n^{2}}{900 r}\left(-\frac{0.0625 \mathrm{~s}^{4} \sin ^{2}(\beta) \cos ^{2}(\beta)}{\sqrt[3]{R_{1}{ }^{2}-0.25 s^{2} \sin ^{2}(\beta)}}\right. \\
& \left.-\frac{s^{2} \cos (2 \beta)}{4 \sqrt{R_{1}{ }^{2}-0.25 s^{2} \sin ^{2}(\beta)}}+\frac{s \cos (\beta)}{2}\right)
\end{aligned}
$$

\section{Data Availability}

The experiment is carried out on a PYGB1821 cone crusher. Base angle of mantle is $50.5^{\circ}$. Nip angle is $21^{\circ}$. Eccentric angle is $2.5^{\circ}$. Closed set setting is $19 \mathrm{~mm}$. Speed is $300 \mathrm{rpm}$. As shown in Figure 6, the wear amount is measured by a HT-307 Distance Measuring Device from HCJYET Inc. The feed particle size distribution is obtained by RX-29-10 sieve shaker from W.S. Tyler. Experimental data can be obtained by sending an email to b20150253@xs.ustb.edu.cn.

\section{Conflicts of Interest}

The authors declare that there are no conflicts of interest regarding the publication of this paper.

\section{Acknowledgments}

This work was supported by the National Key Research and Development Program of China (no. 2016YFC0600805).

\section{References}

[1] M. Bengtsson, G. Asbjörnsson, E. Hulthén, and M. Evertsson, "Towards dynamical profit optimization of comminution circuits," Minerals Engineering, vol. 103-104, pp. 14-24, 2017.

[2] Y.-X. Peng, X. Ni, Z.-C. Zhu et al., "Friction and wear of liner and grinding ball in iron ore ball mill," Tribology International, vol. 115, pp. 506-517, 2017.
[3] P. W. Cleary and P. Owen, "Effect of liner design on performance of a HICOM ${ }^{\circledR}$ mill over the predicted liner life cycle," International Journal of Mineral Processing, vol. 134, pp. 11-22, 2015.

[4] R. S. Sinha and A. K. Mukhopadhyay, "Reliability centered maintenance of cone crusher: a case study," International Journal of Systems Assurance Engineering and Management, vol. 6, no. 1, pp. 32-35, 2015.

[5] J. Terva, V.-T. Kuokkala, K. Valtonen, and P. Siitonen, "Effects of compression and sliding on the wear and energy consumption in mineral crushing," Wear, vol. 398-399, pp. 116-126, 2018.

[6] K. Holmberg, P. Kivikytö-Reponen, P. Härkisaari, K. Valtonen, and A. Erdemir, "Global energy consumption due to friction and wear in the mining industry," Tribology International, vol. 115, pp. 116-139, 2017.

[7] S. Ala-Kleme, P. Kivikytö-Reponen, J. Liimatainen, J. Hellman, and S.-P. Hannula, "Abrasive wear properties of tool steel matrix composites in rubber wheel abrasion test and laboratory cone crusher experiments," Wear, vol. 263, no. 1-6, pp. 180-187, 2007.

[8] P. Clarke, I. Elias, and J. Kautto, "Laser scanning for complete wear history capture and life cycle data analysis in the mining industry," International Journal of COMADEM, vol. 18, no. 4, pp. 21-25, 2015.

[9] M. Lindqvist and C. M. Evertsson, "Development of wear model for cone crushers," Wear, vol. 261, no. 3-4, pp. 435-442, 2006.

[10] G. Asbjörnsson, E. Hulthén, and M. Evertsson, "Modelling and dynamic simulation of gradual performance deterioration of a crushing circuit - Including time dependence and wear," Minerals Engineering, vol. 33, pp. 13-19, 2012.

[11] Y. Ma, X. Fan, and Q. He, "Wear prediction of multi-material time-varying chamber of cone crusher," Journal of Central South University (Science and Technology), vol. 47, no. 4, pp. 1121-1127, 2016.

[12] Y. Ma, X. Fan, and Q. He, "Prediction of cone crusher performance considering liner wear," Applied Sciences (Switzerland), vol. 6, no. 12, p. 404, 2016.

[13] G. W. Delaney, R. D. Morrison, M. D. Sinnott, S. Cummins, and P. W. Cleary, "DEM modelling of non-spherical particle breakage and flow in an industrial scale cone crusher," Minerals Engineering, vol. 74, pp. 112-122, 2015.

[14] J. Franke, P. W. Cleary, and M. D. Sinnott, "How to account for operating condition variability when predicting liner operating life with DEM - A case study," Minerals Engineering, vol. 73, pp. 53-68, 2015.

[15] J. Li. Study on, crushing process of cone crusher based on EDEM. [Msc, thesis], University of Science and Technology, Beijing, China, 2016.

[16] D. Boemer and J.-P. Ponthot, "A generic wear prediction procedure based on the discrete element method for ball mill liners in the cement industry," Minerals Engineering, vol. 109, pp. 55-79, 2017.

[17] N. S. Weerasekara, M. S. Powell, P. W. Cleary et al., "The contribution of DEM to the science of comminution," Powder Technology, vol. 248, pp. 3-24, 2013.

[18] J. Wang, Z. Ren, J. Chen, and L. Chen, "Study on Rail Profile Optimization Based on the Nonlinear Relationship between Profile and Wear Rate," Mathematical Problems in Engineering, vol. 2017, Article ID 6956514, 12 pages, 2017.

[19] C. S. Mahlami and X. Pan, "Challenges and developments of hadfield manganese steel castings based on service life," in Proceedings of the 71st World Foundry Congress: Advanced Sustainable Foundry, WFC 2014, Spain, May 2014. 
[20] J. Tang, B. Shi, H. Yu, R. Wang, and W. Zhang, "Design of crusher liner based on time-varying uncertainty theory," in Proceedings of the 2nd International Seminar on Advances in Materials Science and Engineering, IOP Publishing, Singapore, 2017.

[21] R. Sinha and A. Mukhopadhyay, "Wear characterization and modelling of Mn-steel liners used in rock crushers," Perspectives in Science, vol. 8, pp. 374-376, 2016.

[22] J. F. Archard, "Contact and rubbing of flat surfaces," Journal of Applied Physics, vol. 24, no. 8, pp. 981-988, 1953.

[23] R. Liu, B. Shi, G. Li, and H. Yu, "Influence of Operating Conditions and Crushing Chamber on Energy Consumption of Cone Crusher," Energies, vol. 11, no. 5, p. 1102, 2018.

[24] P. P. Rosario, R. A. Hall, and D. M. Maijer, "Liner wear and performance investigation of primary gyratory crushers," Minerals Engineering, vol. 17, no. 11-12, pp. 1241-1254, 2004.

[25] M. Lindqvist and C. M. Evertsson, "Linear wear in jaw crushers," Minerals Engineering, vol. 16, no. 1, pp. 1-12, 2003. 


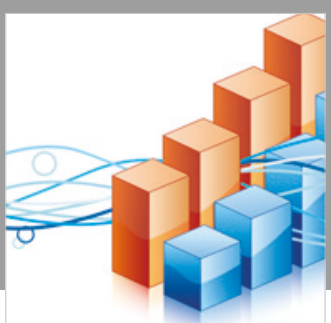

Advances in

Operations Research

\section{-n-m}
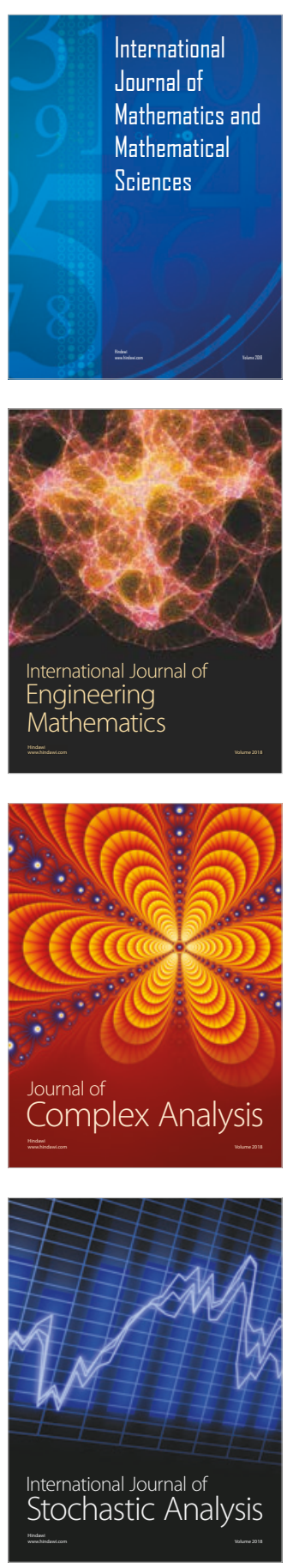
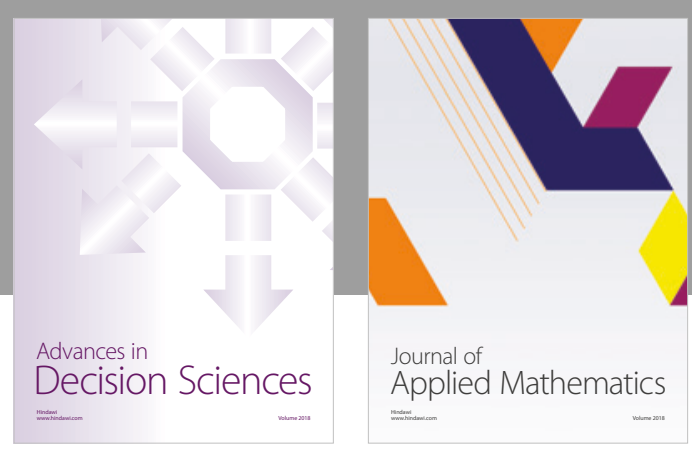

Journal of

Applied Mathematics
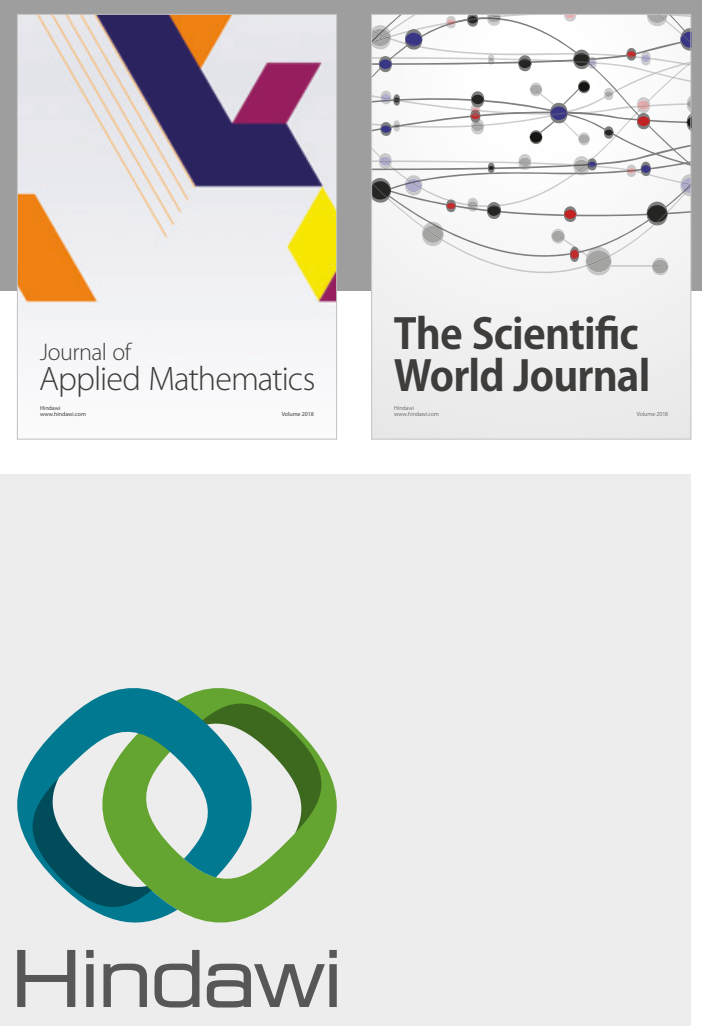

Submit your manuscripts at

www.hindawi.com

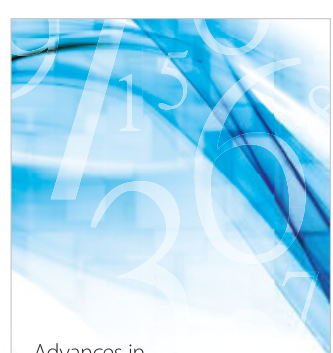

Advances in
Numerical Analysis
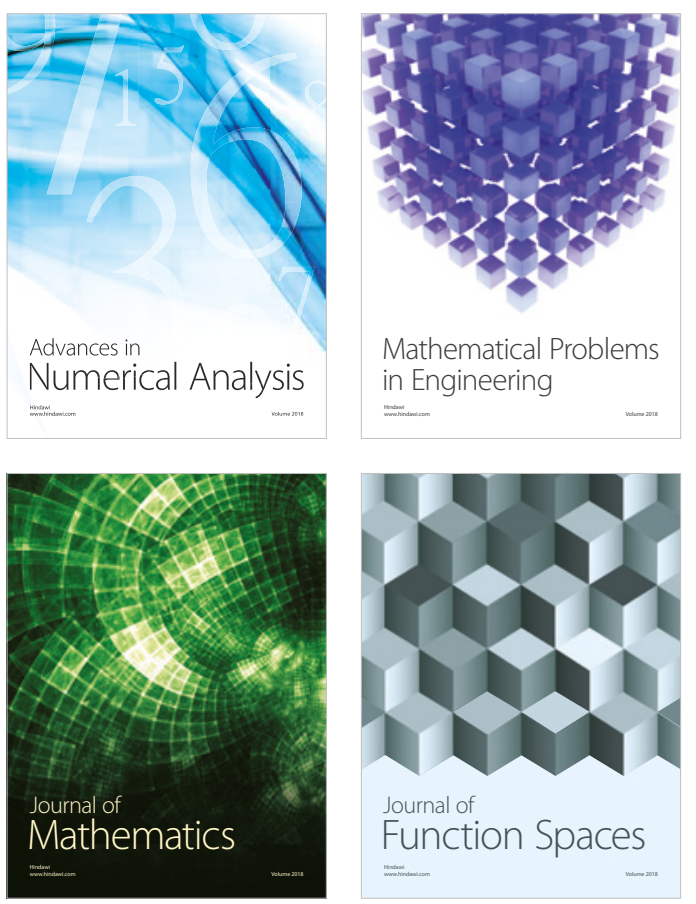

Mathematical Problems in Engineering

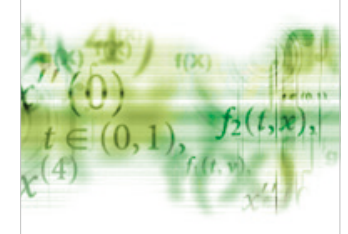

International Journal of

Differential Equations

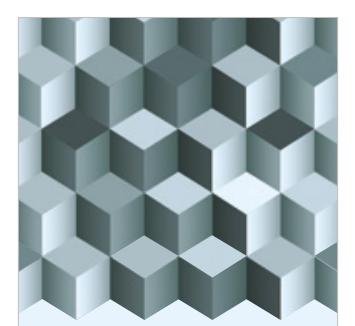

Journal of

Function Spaces

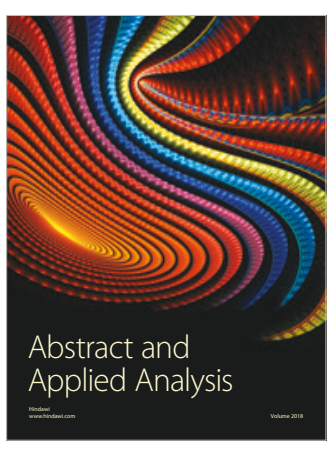

The Scientific

World Journal

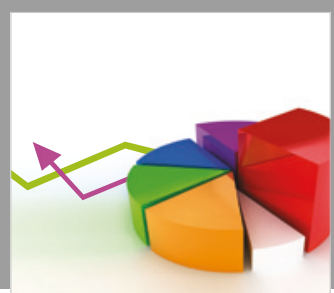

Journal of

Probability and Statistics
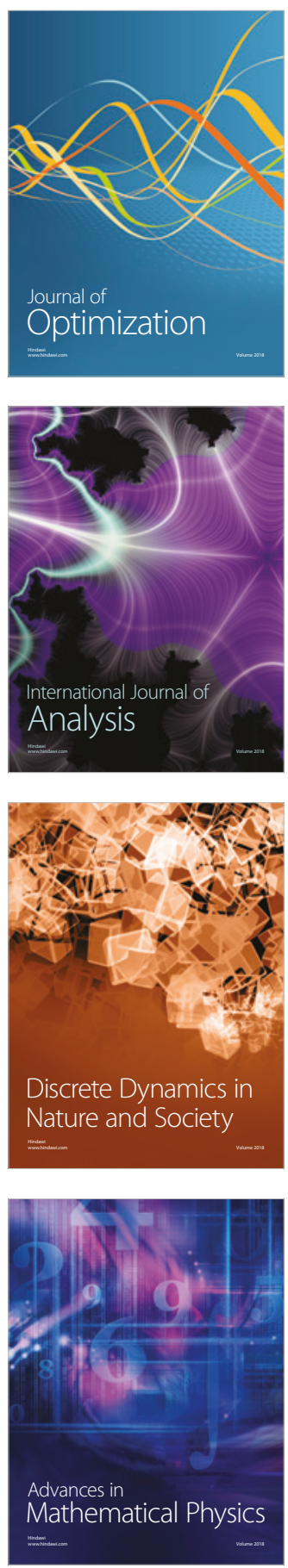